\title{
Biomasa one of the most effective types of fuel for the production of warmth
}

\author{
$\underline{\text { Yurii Sniezhkin }}$ \\ Heat and mass transfer in heat engineering, Institute of engineering \\ thermophysics National Academy of Sciences of Ukraine, Ukraine, Kyiv, street Bulakhovskogo 2, \\ 1snezhkin@gmail.com
}

\begin{abstract}
These uses of biomass are presented in the world and prospects of her use in Ukraine as a fuel from refurbishable energy sources. The examples of equipment, developed in the institute of engineering thermophysics National Academy of Sciences of Ukraine are resulted, which uses a biofuels and the ecological use provides him.
\end{abstract}

Keywords - renewable energy sources, biomass, biofuels, thermal energy, heat output, boilers, furnaces, dryers, ecology, heat utilizers, cyclones.

\section{Introduction}

Today in the world produced over $12 \%$ of all energy from refurbishable energy sources (RES). If to look at the structure of RES, then evidently, that over $10 \%$ she is folded by energy from biomass. If all energy from RES to take for $100 \%$, then over $72 \%$ she is folded by hard biomass. Statistical data show to us, that in the countries of EU at the production of warmth energy from biomass occupies 3 places after natural gas and coal. Thus in some countries of EU this fate considerably anymore. Yes, in Sweden part of energy from biomass in a general energy consumption anymore $20 \%$, and in the production of warmth over $60 \%$. In Austria of $15,5 \%$ and $39 \%$ accordingly, in Germany of $7,1 \%$ and $16,4 \%$ and for our neighbours to Lithuania of $24,4 \%$ and $16 \%$. Why does бiomaca occupy one of main places in RES? Because unit of energy from biomass in 1,6 - 3,3 times below than cost of unit of energy from natural gas. [1]

And what do we have in Ukraine with RES? The statistics show that Ukraine imports more than $60 \%$ of energy resources, and on this indicator has approximately the same indicators as Lithuania 64\% and Germany 61.3\%. But in these countries REE is used much better. Today, Ukraine has about $7 \%$ and plans to reach $11 \%$ of use of RES in general energy consumption by 2020 , at the same time Germany plans this indicator at the level of $18 \%$, Lithuania is even more than $40 \%$. [2]

In Ukraine, the highest growth rate of RES is biomass. According to the Energy Strategy of Ukraine, by 2035 biomass, biofuels and waste should be in $2020-4 \%$, and $2035-11 \%$ in the overall structure of supply of primary energy. And these are the highest rates among other RES sources. Forecast indicators show that in the production of thermal energy, the share of RES will be in $2020-12 \%$, and in 2035 rubles. - 40\%.[3]

This growth is planned to be achieved at the expense of increased use of RES in industry, district heating and the budget sphere. The use of biofuels in the production of energy has another feature in the development of it, there are new jobs. This indicator is the highest among other sources of energy. Thus, by 2020 more than 20,000 jobs will be created, and in 2035 the forecast will be 97,000 jobs.

And is there the necessary energy potential of biomass in Ukraine. Calculations show that the waste of the agro-industrial complex, namely straw of grain crops, rapeseed, by-products of corn production for grain and sunflower, is more than 8 million tons. In this case, their use is 30$4 \%$ of the available resources. And energy crops of about 5 million tons of AD and woody biomass (firewood, woodworking waste, drywall, etc.), biodiesel, bioethanol, peat and others. In total, this is about 21 million tons.

For the successful use of biomass it is necessary to have equipment that can work efficiently on this diverse raw material. The institute has created a solid-water heater, unified boiler KVU0,5 t for heating and hot water supply of residential, industrial and administrative facilities in closed systems of heat supply, which works on different types of solid biofuels. The nominal heat 
output of the boiler is $0.5 \mathrm{MW}$, the regulation range is $40-100 \%$, the maximum efficiency is $90 \%$, the estimated service life is 15 years, the payback period is up to 18 months. More than 70 such boilers have been introduced.

For the heating of residential and auxiliary premises with an area of 40 to $140 \mathrm{~m} 2$ and cooking, a set of furnaces of various capacity "Record" (OPV-1) was developed. OPV-1 works on different types of solid biofuels and maintains a given indoor temperature with minimal fuel consumption. Long-term combustion of fuel (not less than 6 hours at one bookmark). Nominal heat output is $2-4 \mathrm{~kW}$. The additional furnace equipment allows to produce electricity $12-1-\mathrm{W}$. OPV-1 meets the requirements of State standard of Ukraine 3075-95 and Fire safety rules in Ukraine. About 500 stoves have been introduced.

The heat generator with a heat output of $0.7 \mathrm{MW}$ works on different types of biofuels. It is made up of three units: a combustion and mixing unit (firebox) and two tanks with a heat output of $350 \mathrm{~kW}$ each. The trolleys, in connection with the peculiarities of work, include in their composition: bunkers for fine fractional fuel, a small fractional fuel storage device, a loading device for large pieces of fuel and combustion devices of a compressed layer, a heat generator introduced in the technological process of drying mineral fertilizers in a drum dryer.

The work of equipment that uses biomass should not only be energy efficient, but also meet all the necessary environmental standards. The Institute developed a heat utilizer for waste water from boilers and furnaces, which heats the water of the heat supply system by utilizing the heat of clean and dusty waste gas from boilers and industrial furnaces of various uses. Heat utilizer with a heat output of 0.3-1.2 MW intensifies heat exchange due to the use of pipes with ring turbulators, which allows to reduce the metal capacity and equipment dimensions from 1,52 times. The payback period is up to 1 year.

The centrifugal filter is designed to purify the airflow from ash and dust. The efficiency of dust capture in a centrifugal filter is $92-98 \%$. The simplicity of design and reliability in operation, as well as the absence of filtering elements, makes it the most effective cyclone of the present.

Widespread use of biomass constrains a number of factors. So, the prices for natural gas for the population and heatkomunenergo are not yet marketable (40\% lower). Lack of solid biofuel market. Lack of stimulation of electricity production from biomass and biogas. As a result, it is possible to conclude that today biomass is one of the most effective types of RES.

\section{References}

[1] H.H. Heletukha, T.A. Zheliezna, S.V. Drahniev, A.I. Bashtovyi, "Analysis of the possibilities of production and consumption of fuel briquettes from biomass of agricultural origin in Ukraine. Part $1 »$, Industrial Heat Engineering, vol. 40, no.4, pp. 62-68, 2018.

[2] H.H. Heletukha, T.A. Zheliezna, A.I Bashtovyi, H.I. Heletukha, "An overview of the best practices in organizing the work of the biofuel market in EU countries", Promyslova Tekhnika, vol. 39, no. 5, pp. 108-112, 2017.

[3] T.A. Zheliezna, A.I. Bashtovyi, "Analysis of the main trends in the development of bioenergy in the European Union", Industrial Heat Engineering, vol. 40, no.3, pp. 70-75, 2018. 